\title{
Enantioselective Silver and Amine Co-catalyzed Desymmetrizing Cycloisomerization of Alkyne-linked Cyclohexanones
}

\author{
Rubén Manzano, ${ }^{[a]}$ Swarup Datta, ${ }^{[a]}$ Robert S. Paton ${ }^{*[a]}$ and Darren J. Dixon*[a]
}

\begin{abstract}
A silver(I) and amine co-catalyzed desymmetrization of 4propargylamino cyclohexanones for the direct enantioselective synthesis of 2-azabicyclo[3.3.1]nonanes is described. Exploiting reactivity arising from dual activation of the pendant terminal alkyne by silver(I) and the ketone moiety through transient enamine formation, this synthetically relevant transformation is easy to perform, efficient and broad in scope. High enantioselectivity (up to $96 \%$ ee) was achieved by exploiting a significant matching effect between the chirality of a cinchona alkaloid-derived aminophosphine ligand for the silver(I) salt and the 2-bis(aryl)methylpyrrolidine catalyst which was rationalized by DFT calculations. This allowed for the preparation of both enantiomers of the bicyclic product with nearidentical stereocontrol.
\end{abstract}

In recent years, the demand for ever-increasing efficiency in the synthesis of structurally complex and stereochemically defined molecular constructs has spawned numerous lines of research in the field of enantioselective catalysis. One particular strand, where multiple catalytically competent and compatible species are employed simultaneously to achieve reactivity unattainable by a single catalytic entity alone, has been particularly successful..[1] In this regard, the co-operative combination of aminocatalysis and transition metal catalysis has been demonstrated to be a powerful and versatile catalytic strategy for the enantioselective construction of C-C bonds, ${ }^{[2]}$ which has found applications in both library synthesis and natural product synthesis alike. ${ }^{[3]}$

The use of terminal alkynes as electrophilic partners for carbonyl compounds in co-operative metal and amine cocatalysis was first reported independently by our group and the Kirsch group in 2008. ${ }^{[4]}$ Racemic cyclopentane derivatives were prepared by a copper-catalyzed cascade reaction between $\alpha, \beta$ unsaturated ketones and propargylmalonates in the former case, and by a gold-catalyzed intramolecular cyclization of 1,7-ynals in the latter. Enantioselective variants of both 5-endo-dig cyclizations with aldehydes as starting materials were later disclosed. ${ }^{[5],[6]}$

In a continuation of our research program into expanding the synthetic possibilities of co-operative co-catalytic transformations we took inspiration from nature. A wide variety of natural products and biologically relevant molecules contain the morphan core (2-azabicylo[3.3.1]nonane) in their structures, including the daphniphyllum and strychnos alkaloid families, ${ }^{[7]}$

[a] Dr. R. Manzano, Dr. S. Datta, Prof. Dr. R. S. Paton, Prof. Dr. D. J. Dixon Department of Chemistry, Chemistry Research Laboratory

University of Oxford

Mansfield Road, Oxford OX1 3TA (UK)

E-mail: darren.dixon@chem.ox.ac.uk and accordingly the development of new, efficient and stereoselective methods for the construction of this motif is highly desirable. In this context, an organocatalyzed intramolecular Michael addition to $\alpha, \beta$-unsaturated esters ${ }^{[8 \mathrm{a}]}$ and an enantioselective arylation of cyclohexanones have been reported. ${ }^{[8 b]}$

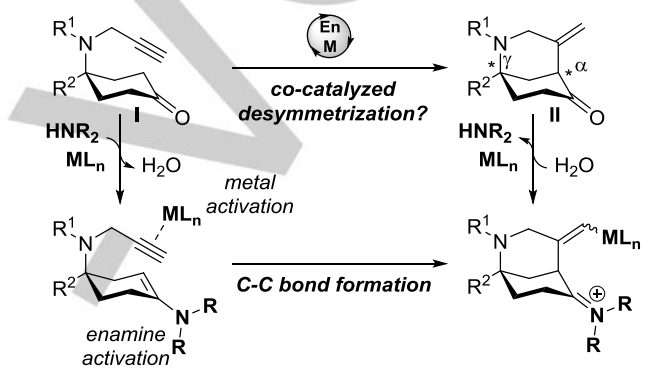

Scheme 1. Metal and amine co-catalyzed desymmetrization concept.

We envisaged that an enantioselective desymmetrizing ${ }^{[9]}$ cycloisomerization of prochiral scaffold I (Scheme 1) to afford the 6,6-bicyclic morphan skeleton II could possibly be realized using a co-operative metal and amine co-catalyst system. Under appropriate reaction conditions, the aminocatalyst would generate in situ a nucleophilic enamine intermediate, which would be poised to react intramolecularly with the pendant alkyne when suitably activated by a 'soft' late transition metal ion, such as a copper or silver species. ${ }^{[10]}$ Such an enantioselective transformation to a strained 6,6-bicyclic morphan core has not previously been described despite its potential use in synthesis and herein we wish to disclose our findings.

Our hypothesis was validated following a series of experiments with substrate $\mathbf{1 a}$, which was accessible on scale from simple commercial starting materials. Treatment of 1a with catalytic amounts of pyrrolidine, $\mathrm{Cu}(\mathrm{OTf})_{2}$ and triphenylphosphine [as a reducing agent and ligand for copper] in DMF at $70{ }^{\circ} \mathrm{C}$ for 12 hours provided the racemic morphan product 2a in good yield (Scheme 2). Control experiments omitting any one of these three components produced no or insignificant amounts of $\mathbf{2 a}$ (see $\mathrm{SI}$ for details). Additionally, $\mathrm{N}$ methylpyrrolidine was found to be catalytically incompetent in the reaction. Taken together these preliminary studies suggested that both enamine activation of the ketone group and transition metal activation of the alkyne were required for a productive carbocyclization.
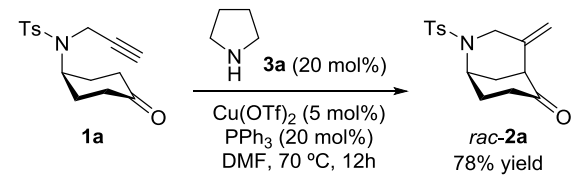

Scheme 2. Proof of concept. 
Consequently, we continued our investigations by evaluating the enantioselective version of this reaction. Considering the literature precedents ${ }^{[4-6]}$ and the preliminary studies described above, an obvious approach was to investigate the combination of a soft transition metal species with chiral amines and/or chiral phosphines.

Initial experiments demonstrated that a combination of chiral 2-bis(aryl)methylpyrrolidines (3d-e) and cinchonidine-derived aminophosphine $(\mathbf{4 a})^{[11]}$ in conjunction with a copper salt made an excellent starting point for a co-catalytic system (Table 1). Primary amines or proline (3c) provided very low enantiocontrol and variable reactivity (entry 2 and $\mathrm{SI}$ for full details). Although the typically successful diarylprolinol silyl ether catalyst $\mathbf{3 b}$ was inefficient in this transformation (entry 1), ${ }^{[12]}$ a sterically less demanding desilyloxy derivative ${ }^{[13]}(\mathbf{3 d})$ was found to be very promising, especially when combined with the readily available cinchonidine-derived aminophosphine 4a (entries 3-4). Whereas copper salts provided enhanced reactivity, silver acetate induced higher enantiocontrol (entries 4-5) and consequently the remainder of our studies focused on silver salts as the metal cocatalyst. Modifications to the catalyst structure $\mathbf{3 d}$ led to the identification of the 3,5-bis(trifluoromethyl)phenyl-derived pyrrolidine (3e) as the most enantioselective catalyst, which afforded $2 \mathbf{a}$ in $92 \%$ ee (entry 6 ).

The poor catalytic turnover was greatly improved by the use of inexpensive 2,4-dinitrophenol (DNP) as an acidic additive (entry 7). ${ }^{[14,15]}$ Furthermore, protic solvents had previously been reported to accelerate some reactions ${ }^{[14]}$ and indeed 2-propanol was found to be the optimal solvent for this transformation (entry 8). It is likely that the protic medium assists the protodemetallation step ${ }^{[16]}$ and/or facilitates enamine formation. ${ }^{[17]}$ After fine tuning of the silver source and the temperature (see SI for details), we found that the combination of chiral pyrrolidine 3e, $\mathrm{AgNTf}_{2}$, aminophosphine $4 \mathrm{a}$ and 2,4dinitrophenol smoothly promoted the targeted reaction in 2propanol at $60 \stackrel{\circ}{\circ}$, and product $2 \mathbf{a}$ was isolated quantitatively with $95 \%$ ee (entry 9 ). The related ligand $\mathbf{4 b}$, possessing an $\mathrm{N}$ Me group on the amide, provided good enantioselectivity, but a very low yield (entry 10). Control experiments showed that all components were either essential or important for the excellent reactivity and enantioselectivity.

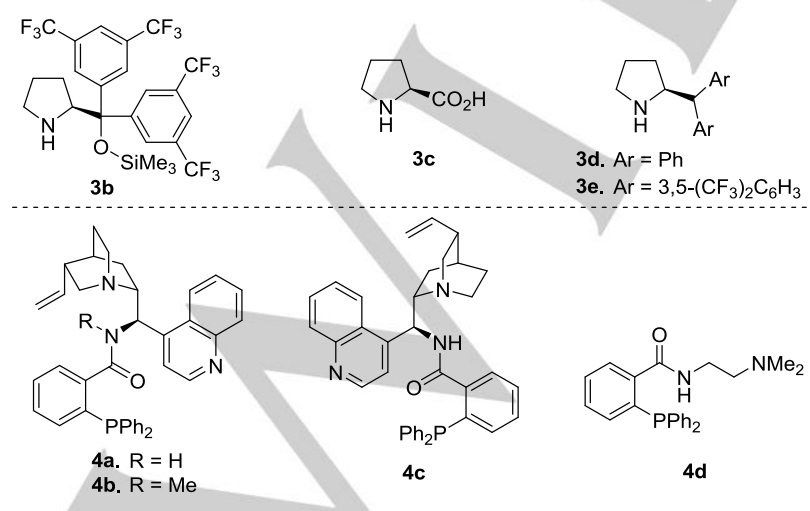

Figure 1. Chiral amines and aminophosphine ligands.
Table 1. Development of an enantioselective variant.

\begin{tabular}{|c|c|c|c|c|c|}
\hline & & $\begin{array}{r}3(2 \\
\text { metal } \\
\mathrm{PPh}_{3} \\
\mathrm{THF}, \mathrm{s}\end{array}$ & $\begin{array}{l}\mid \%) \\
\text { ce M } \\
\text { nol\%) } \\
\\
72 \mathrm{~h}\end{array}$ & & \\
\hline Entry ${ }^{[a]}$ & 3 & M & ligand & \%yield ${ }^{[b]}$ & $\% e e^{[c]}$ \\
\hline 1 & $3 b$ & $\mathrm{Cu}(\mathrm{OTf})_{2}$ & $\mathrm{PPh}_{3}$ & 20 & 15 \\
\hline 2 & $3 c$ & $\mathrm{Cu}(\mathrm{OTf})_{2}$ & $\mathrm{PPh}_{3}$ & 82 & 0 \\
\hline 3 & $3 d$ & $\mathrm{Cu}(\mathrm{OTf})_{2}$ & $\mathrm{PPh}_{3}$ & 74 & 52 \\
\hline 4 & $3 d$ & $\mathrm{Cu}(\mathrm{OTf})_{2}$ & $4 a$ & 70 & 71 \\
\hline 5 & $3 d$ & $\mathrm{AgOAc}$ & $4 a$ & 20 & 83 \\
\hline 6 & $3 e$ & $\mathrm{AgOAc}$ & $4 a$ & 11 & 92 \\
\hline $7^{[\mathrm{d}]}$ & $3 e$ & $\mathrm{AgOAc}$ & $4 a$ & 82 & 91 \\
\hline $8^{[\mathrm{d}, \mathrm{e}]}$ & $3 e$ & $\mathrm{AgOAc}$ & $4 a$ & 99 & 90 \\
\hline $9^{[d, e, f]}$ & $3 e$ & $\mathrm{AgNTf}_{2}$ & $4 a$ & 99 & 95 \\
\hline $10^{[\mathrm{d}, \mathrm{e}, \mathrm{f}]}$ & $3 e$ & $\mathrm{AgNTf}_{2}$ & $4 b$ & 15 & 90 \\
\hline
\end{tabular}

[a] Conditions: 1a $(0.1 \mathrm{mmol}), 3$ (20 mol\%), ligand (20 mol\%), Cu(OTf) $)_{2}(5$ mol\%) or AgOAc (10 mol\%) in THF $(0.5 \mathrm{~mL})$ at $90 \stackrel{\circ}{\circ} \mathrm{C}$ for $72 \mathrm{~h}$. [b] Isolated yield. [c] ee determined by chiral HPLC. [d] 2,4-Dinitrophenol $(20 \mathrm{~mol} \%)$ was used. [e] $i-\mathrm{PrOH}$ instead of THF. [f] At $60 \stackrel{\circ}{\circ}$.

As initially proposed, a significant match/mismatch effect was in operation between both chiral components of the catalytic system (Scheme 3 ). The matched combination of $R$-configured pyrrolidine ent-3e with cinchonine-derived aminophosphine 4c afforded the enantiomeric morphan product ent-2a with the same high efficiency and high enantioselectivity as $\mathbf{3 e}$ and $\mathbf{4 a}$ (Scheme 3, compare top-left and bottom-right). ${ }^{[18]}$ On the contrary, the use of the mismatched pairs $3 e / 4 c$ or ent-3e/4a (Scheme 3, compare bottom-left, top-right) provided the product with a diminished enantioselectivity. The use of achiral pyrrolidine $\mathbf{3 a}$ and cinchonidine-derived aminophosphine $\mathbf{4 a}$ gave rise to minimal enantiocontrol in the reaction (36\% ee), whereas the use of achiral ligand $\mathbf{4 d}$ and chiral pyrrolidine $\mathbf{3 e}$ afforded product $\mathbf{2 a}$ with a substantial $80 \%$ ee. These results demonstrate that the pyrrolidine is exerting the dominant stereocontrolling force in the reaction.

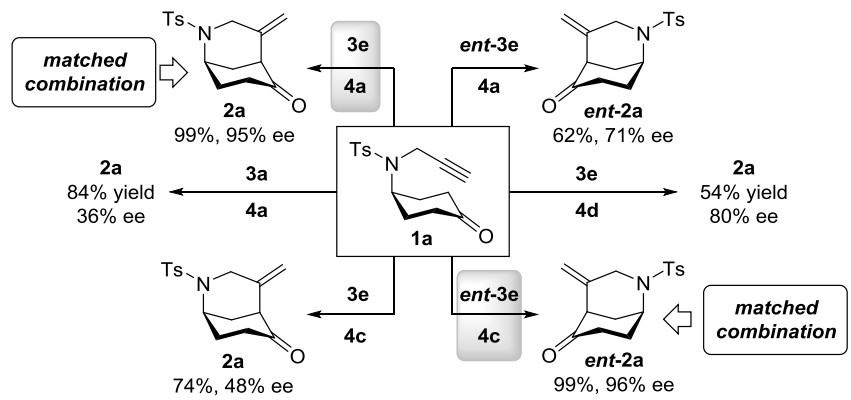

Scheme 3. Match/mismatch effects. (Conditions as for Table 1, entry 9).

With a reliable and optimal procedure in hand, we then assessed the scope of this enantioselective morphan-generating desymmetrization reaction (Scheme 4). Electron-rich and electron-poor aromatic sulfonamides (1)-c), as well as an aliphatic one (1e) were good substrates affording products in 
high yield and enantioselectivity. It was observed that strongly electron-deficient sulfonamides, like 4-nosyl and triflyl derivatives $\mathbf{2} \mathbf{d}$ and $\mathbf{2 f}$, were obtained with a moderate yield but good enantioselectivity. Carbamates $\mathbf{1 h}$-i were well-tolerated and the respective products $2 \mathrm{~h}-\mathbf{i}$ were obtained with good enantiocontrol. Acetamide protected product $\mathbf{2} \mathbf{j}$ was afforded in only moderate yield and with a slightly reduced enantiocontrol. Importantly, additional substituents at the 4-position of the cyclohexanone ring were perfectly tolerated, and a variety of morphan products possessing a quaternary stereocenter (2k-n) were prepared in excellent yields with high enantioselectivity.
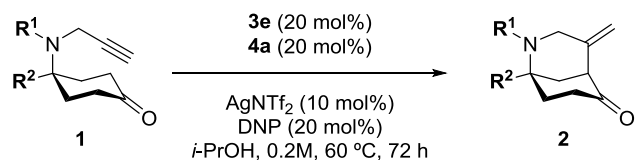

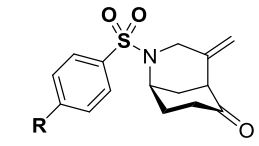

2a. $\mathrm{R}=\mathrm{Me} \quad 99 \%, 95 \%$ ee 2b. $\mathrm{R}=\mathrm{OMe} \quad 87 \%, 93 \%$ ee 2c. $\mathrm{R}=\mathrm{CF}_{3} \quad 80 \%, 90 \%$ ee 2d. $\mathrm{R}=\mathrm{NO}_{2} \quad 40 \%, 93 \%$ ee

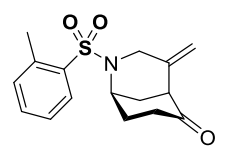

2g. $56 \%, 86 \%$ ee

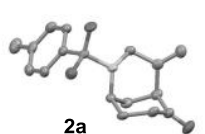

2a
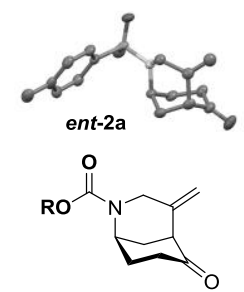

2h. $R={ }^{t} \mathrm{Bu} 38 \%, 90 \%$ ee 2i. $\mathrm{R}=\mathrm{Bn} 53 \%, 87 \%$ ee

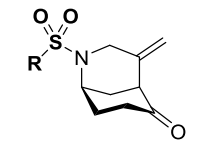

2e. $\mathrm{R}=\mathrm{Me} \quad 80 \%, 91 \%$ ee 2f. $\mathrm{R}=\mathrm{CF}_{3} 29 \%, 86 \%$ ee

2j. $34 \%, 74 \%$ ee ${ }^{[b]}$
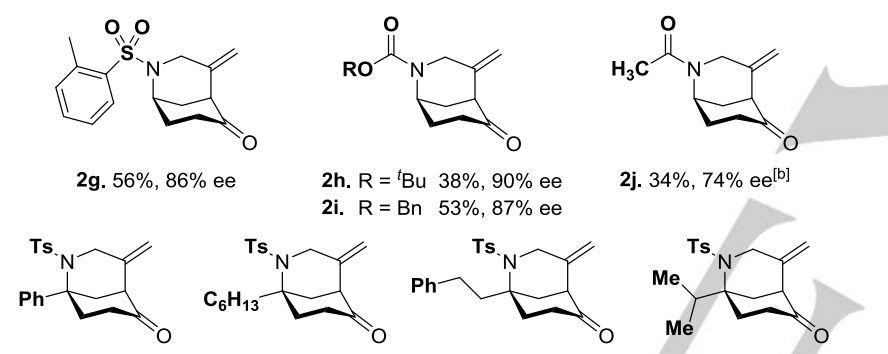

$\begin{array}{lll}\text { 2k. } 99 \%, 93 \% \text { ee } & \text { 2l. } 96 \%, 90 \% \text { ee } & \text { 2m. } 99 \%, 95 \% \text { ee }\end{array}$ [a] ent-3e and $4 c$ instead of $3 e$ and $4 a$. [b] At $90{ }^{\circ} \mathrm{C}$

2n. $99 \%, 80 \%$ ee

Scheme 4. Scope of the enantioselective desymmetrization reaction. [Conditions: 1 (0.2 mmol), 3e (20 mol\%), 4a (20 mol\%), AgNTf 2 (10 mol\%) and 2,4-dinitrophenol $(20 \mathrm{~mol} \%)$ in 2-propanol $(1.0 \mathrm{~mL})$ at $60 \stackrel{\circ}{\mathrm{C}}$ for $72 \mathrm{~h}$. Isolated yield. ee determined by chiral HPLC].

Based on a quinine-derived aminophosphine-silver complex recently characterized by $\mathrm{X}$-ray analysis, ${ }^{[19]}$ we have performed DFT computations of enamine intermediates and competing transition structures (TSs) which account for the stereochemical outcome of the reaction (Scheme 5). ${ }^{[20]}$ The aminophosphinesilver complex is likely formed rapidly by coordination of the quinuclidine nitrogen, the phosphorus atom and the amide nitrogen to the silver center. Condensation of the pyrrolidine catalyst with the carbonyl group of 1a generates a nucleophilic enamine intermediate poised for $\mathrm{C}-\mathrm{C}$ bond formation upon alkyne activation. The terminal alkyne of this adduct can be accommodated as a $\pi$-ligand by the silver complex. Although the s-trans rotamer of aldehyde-derived enamines is clearly favored, ${ }^{[21]}$ the reactive conformation of ketone-derived enamines depends on the functionality at the 2-position of the pyrrolidine ring, as demonstrated in the well-studied reaction between cyclohexanone and nitrostyrene catalyzed by chiral pyrrolidines. ${ }^{[22]}$ For reactions catalyzed by pyrrolidines with a substituent able to establish $\mathrm{H}$-bond interactions with the substrate, s-trans enamines have been proposed and calculated, ${ }^{[23]}$ but when the substituent on the catalyst acts simply as a bulky group, the stereochemical outcome is explained through $s$-cis enamines. ${ }^{[24]}$ Significantly, in this type of transformations it has also been observed that, with the same catalyst system, the enantioselectivity is reversed when an aldehyde is used instead of a ketone. ${ }^{[25]}$ With catalyst $\mathbf{3 d}$ an SMD-M06-2X/def2-TZVP//def2-SVP conformational analysis reveals a $3 \mathrm{kcal} / \mathrm{mol}$ preference for the $s$-cis enamine geometry in the ground state, in which the sterically demanding diarylmethyl group is positioned preferably above the flat olefinic $\mathrm{sp}^{2}$ carbon rather than above the bulkier tetrahedral $\mathrm{sp}^{3}$ carbon by $3 \mathrm{kcal} / \mathrm{mol}$. This preference is maintained in the competing TSs, in which the electrophile must approach from the opposite side to this bulky group. A secondary $\mathrm{H}$-bonding interaction ( $\mathrm{N}$ $\mathrm{H}---\mathrm{O}<2.5 \AA$ ) between sulfonate and amidic $\mathrm{N}-\mathrm{H}$ group of the aminophosphorane $\mathbf{4 a}$ or $\mathbf{4 d}$ was found in the computed TSs. ${ }^{[26]}$ For chiral aminophosphine $\mathbf{4 a}$, the matched TS has a shorter $\mathrm{N}$ $\mathrm{H}$---O interaction to the sulfonate group than in the mismatched case $(1.96 \AA$ vs. $2.11 \AA$ ) - the greater stability reflected by an increase in $\Delta \Delta \mathrm{G}^{\ddagger}$ to $2.8 \mathrm{from} 1.2 \mathrm{kcal} / \mathrm{mol}$ with achiral $4 \mathrm{~d}$. The low efficiency of ligand $\mathbf{4 b}$, with an $\mathrm{N}$-Me group on the amide, compared to that of $4 \mathbf{a}$ (Table 1, entries 9 and 10) indicates the importance of the free $\mathrm{N}-\mathrm{H}$ amide. This assembly would be less favored by more electron deficient sulfonamide groups, in line with the lower reactivity observed for substrates $\mathbf{1 d}$ and $\mathbf{1 f}$ (Scheme 4).

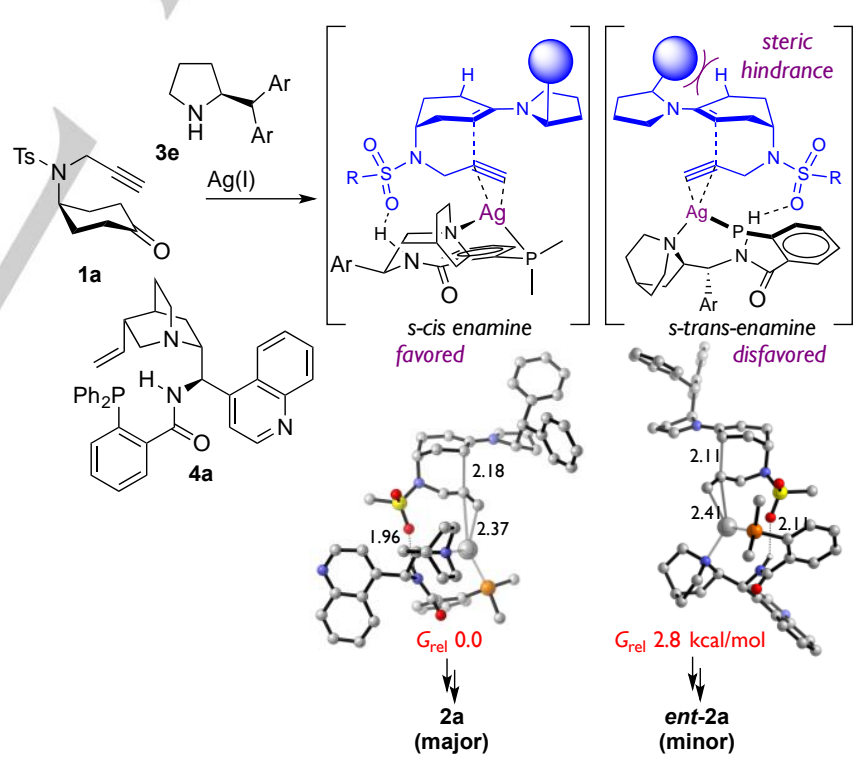

Scheme 5. Computed (SMD-M06-2X/def2-TZVPP//def2-SVP) transition structures for $\mathrm{C}-\mathrm{C}$ formation of major and minor enantiomers.

In summary, we have developed the first enantioselective metal and amine co-catalyzed desymmetrization of 4-propargylamino cyclohexanones for the direct enantioselective synthesis of the morphan core. High enantioselectivity (up to $96 \%$ ee) was achieved by exploiting a significant matching effect between the chirality of the 2-bis(aryl)methylpyrrolidine catalyst and a cinchona alkaloid-derived aminophosphine ligand for the silver(I) 
co-catalyst. Further work to extend the findings of this study and to apply them in natural product synthesis are underway in our laboratory.

\section{Acknowledgements}

R. M. and S. D. thanks the EU commission for IEF (PIEF-GA2013-627232 and PIEF-GA-2009-255080). We thank Dr. Ángel Fuentes and Heyao Shi of the Department of Chemistry, University of Oxford for X-ray analysis, and Oxford Chemical Crystallography Service for use of their instrumentation.

Keywords: aminocatalysis • asymmetric catalysis • cycloisomerization $\cdot$ morphan core $\bullet$ silver catalysis

[1] a) J. Zhou, Multicatalyst System in Asymmetric Catalysis; Wiley: Hoboken, 2014; b) J. Zhou, Chem. Asian J. 2010, 5, 422-434.

[2] Reviews on combination of organocatalysis with metal catalysis: a) S. Afewerki, A. Córdova, Chem. Rev. 2016, 116, 13512-13570; b) M. Meazza, R. Rios, Synthesis 2016, 48, 960-973; c) S. M. Inamdar, V. S Shinde, N. T. Patil, Org. Biomol. Chem. 2015, 8116-8162; d) D.-F. Chen, Z.-Y. Han, X.-L. Zhou, L.-Z. Gong, Acc. Chem. Res. 2014, 47, 2365-2377; e) Y. Deng, S. Kumar, H. Wang, Chem. Commun. 2014, 50 4272-4284; f) Z. Du, Z. Shao, Chem. Soc. Rev. 2013, 42, 1337-1378 g) A. E. Allen, D. W. C. MacMillan, Chem. Sci. 2012, 3, 633-658; h) L. Stegbauer, F. Sladojevich, D. J. Dixon, Chem. Sci. 2012, 3, 942-958; i) C. Zhong, X. Shi, Eur. J. Org. Chem. 2010, 2999-3025; j) Z. Shao, H. Zhang, Chem. Soc. Rev. 2009, 38, 2745-2755.

[3] Selected examples of dual enamine/metal catalysis in total synthesis: a) A. Younai, B.-S. Zeng, H. Y. Meltzer, K. A. Scheidt, Angew. Chem. Int. Ed. 2015, 54, 6900-6904; b) M. A. Schafroth, G. Zuccarello, S Krautwald, D. Sarlah, E. M. Carreira, Angew. Chem. Int. Ed. 2014, 53, 13898-13901; c) F. Bihelovic, R. N. Saicic, Angew. Chem. Int. Ed. 2012 51, 5687-5691; d) S. Afewerki, P. Breistein, K. Pirttilä, L. Deiana, P. Dziedzic, I. Ibrahem, A. Córdova, Chem. Eur. J. 2011, 17, 8784-8788.

[4] a) T. Yang, A. Ferrali, L. Campbell, D. J. Dixon, Chem. Commun. 2008, 2923-2925; b) J. T. Binder, B. Crone, T. T. Haug, H. Menz, S. F. Kirsch, Org. Lett. 2008, 10, 1025-1028.

[5] a) G.-L. Zhao, F. Ullah, L. Deiana, S. Lin, Q. Zhang, J. Sun, I. Ibrahem, P. Dziedzic, A. Córdova, Chem. Eur. J. 2010, 16, 1585-1591; b) K. L. Jensen, P. T. Franke, C. Arróniz, S. Kobbelgaard, K. A. Jørgensen, Chem. Eur. J. 2010, 16, 1750-1753; c) C. Yu, Y. Zhang, S. Zhang, J. He, W. Wang, Tetrahedron Lett. 2010, 51, 1742-1744; d) W. Sun, G. Zhu, L. Hong, R. Wang, Chem. Eur. J. 2011, 17, 13958-13962.

[6] a) B. Montaignac, V. Östlund, M. R. Vitale, V. Ratovelomanana-Vidal, V. Michelet, Org. Biomol. Chem. 2012, 10, 2300-2306; b) B. Montaignac, C. Praveen, M. R. Vitale, V. Michelet, V. Ratovelomanana-Vidal, Chem Commun. 2012, 48, 6559-6561; c) C. Praveen, B. Montaignac, M. R. Vitale, V. Ratovelomanana-Vidal, V. Michelet, ChemCatChem 2013, 5 2395-2404.

[7] Review on the synthesis of the morphan core, see: J. Bonjoch, F. Diaba, B. Bradshaw, Synthesis 2011, 993-1018.

[8] a) A. D. Gammack Yamagata, S. Datta, K. E. Jackson, L. Stegbauer, R. S. Paton, D. J. Dixon, Angew. Chem. Int. Ed. 2015, 54, 4899-4903; b) R.-R. Liu, B.-L. Li, J. Lu, C. Shen, J.-R. Gao, Y.-X. Jia, J. Am. Chem. Soc. 2016, 138, 5198-5201.

[9] Reviews on enantioselective desymmetrizations: a) A. Borissov, T. Q. Davies, S. R. Ellis, T. A. Fleming, M. S. W. Richardson, D. J. Dixon, Chem. Soc. Rev. 2016, 45, 5474-5540, and references therein; b) K. S. Petersen, Tetrahedron Lett. 2015, 56, 6523-6535; c) M. Wang, M. Feng, B. Tang, X. Jiang, Tetrahedron Lett. 2014, 55, 7147-7155; d) E. GarcíaUrdiales, I. Alfonso, V. Gotor, Chem. Rev. 2011, 111, PR110-PR180.
[10] a) Silver in Organic Chemistry (Ed.: M. Harmata), Wiley: Hoboken, 2010. Selected reviews on silver-catalyzed reactions: b) G. Fanga, $X$ Bi, Chem. Soc. Rev. 2015, 44, 8124-8173; c) Q.-A. Chen, D.-S. Wanga, Y.-G. Zhou, Chem. Commun. 2010, 46, 4043-4051; d) M. Naodovic, H. Yamamoto, Chem. Rev. 2008, 108, 3132-3148; d) A. Yanagisawa, T. Arai, Chem. Commun. 2008, 1165-1172.

[11] a) F. Sladojevich, A. Trabocchi, A. Guarna, D. J. Dixon, J. Am. Chem. Soc., 2011, 133, 1710-1713; b) I. Ortín, D. J. Dixon, Angew. Chem., Int Ed., 2014, 53, 3462-3465; c) R. de la Campa, I. Ortín, D. J. Dixon, Angew. Chem., Int. Ed., 2015, 54, 4895-4898.

[12] B. S. Donslund, T. K. Johansen, P. H. Poulsen, K. S. Halskov, K. A Jørgensen, Angew. Chem. Int. Ed. 2015, 54, 13860-13874.

[13] Diarylmethylpyrrolidines have been previously used as organocatalysts See for example: a) K. Juhl, K. A. Jørgensen, Angew. Chem. Int. Ed. 2003, 42, 1498; b) M. Marigo, D. Fielenbach, A. Braunton, A Kjærsgaard, K. A. Jørgensen, Angew. Chem. Int. Ed. 2005, 44, 3703.

[14] Review on additive effects on asymmetric catalysis: L. Hong, W. Sun, D. Yang, G. Li, R. Wang, Chem. Rev. 2016, 116, 4006-4123.

[15] Selected examples of the use of 2,4-dinitrophenol as an efficient cocatalyst in asymmetric reactions: a) C.-S. Da, L.-P. Che, Q.-P. Guo, F.C. Wu, X. Ma, Y.-N. Jia, J. Org. Chem. 2009, 74, 2541-2546; b) X. Chen, J. Wang, Y. Zhu, D. Shang, B. Gao, X. Liu, X. Feng, Z. Su, C. Hu, Chem. Eur. J. 2008, 14, 10896-10899.

[16] a) F. Le Boucher d'Herouville, A. Millet, M. Scalone, V. Michelet Synthesis 2016, 48, 3309-3316; b) M. Wadamoto, H. Yamamoto, J. Am. Chem. Soc. 2005, 127, 14556-14557.

[17] a) J. B. Brazier, K. M. Jones, J. A. Platts, N. C. O. Tomkinson, Angew. Chem. Int. Ed. 2011, 50, 1613-1616; b) M. P. Patil, R. B. Sunoj, J. Org. Chem. 2007, 72, 8202-8215.

[18] CCDC 1520418 (2a) and 1520419 (ent-2a) contain the supplementary crystallographic data for this paper. These data are provided free of charge by The Cambridge Crystallographic Data Centre.

[19] R. de la Campa, A. D. Gammack Yamagata, I. Ortin, A. Franchino, A. L Thompson, B. Odell, D. J. Dixon, Chem. Commun. 2016, 52, 10632 10635.

[20] SMD-M06-2X/def2-TZVP//M06-2X/def2-TZVP calculations were performed using Gaussian 09 rev. D.01, M. J. Frisch et al. Gaussian, Inc., Wallingford CT, 2009. Full details are provided in the Supporting Information.

[21] (a) K. S. Halskov, B. S. Donslund, B. M. Paz, K. A. Jørgensen, Acc. Chem. Res. 2016, 49, 974-986; (b) P. H.-Y. Cheong, C. Y. Legault, J. M. Um, N. Çelebi-Ölçüm, K. N. Houk, Chem. Rev. 2011, 111, 50425137.

[22] (a) Enantioselective Conjugate Addition Reactions via Enamine Activation In Organocatalytic Enantioselective Conjugate Addition Reactions (Eds. J. L. Vicario, D. Badía, L. Carrillo, E. Reyes), RSC Catalysis Series, 2010; (b) D. Almasi, D. A. Alonso, C. Nájera, Tetrahedron: Asymmetry 2007, 18, 299-365.

[23] Selected examples: (a) M. Arnó, R. J. Zaragozá, L. R. Domingo Tetrahedron: Asymmetry 2007, 18, 157-164; (b) J. Wang, H. Li, B. Lou L. Zu, H. Guo, W. Wang, Chem. Eur. J. 2006, 12, 4321-4332; (c) Y.-J. Cao, H.-H. Lu, Y.-Y. Lai, L.-Q. Lu, W.-J. Xiao, Synthesis 2006, 3795 3800 .

[24] (a) S.-W. Wang, J. Chen, G.-H. Chen, Y.-G. Peng, Synlett 2009, $1457-$ 1462; (b) X. Zeng, G. Zhong, Synthesis 2009, 1545-1550; (c) D. Díez, A. B. Antón, P. García, N. M. Garrido, I. S. Marcos, P. Basabe, J. G. Urones, Tetrahedron: Asymmetry 2008, 19, 2088-2091; (d) F. Liu, S. Wang, N. Wang, Y. Peng, Synlett 2007, 2415-2419.

[25] (a) T. Mandal, C.-G. Zhao, Tetrahedron Lett. 2007, 48, 5803-5806; (b) O. Andrey, A. Alexakis, A. Tomassini, G. Bernardinelli, Adv. Synth Catal. 2004, 346, 1147-1168; (c) J. M. Betancort, K. Sakthivel, R. Thayumanavan, F. Tanaka, C. F. Barbas III, Synthesis 2004, 1509 1521

[26] a) C. A. Hunter, Angew. Chem. Int. Ed. 2004, 43, 5310-5324; b) D. A. Adsmond, D. J. W. Grant, J. Pharm. Sci. 2001, 90, 2058-2077. 


\section{Entry for the Table of Contents}

\section{COMMUNICATION}

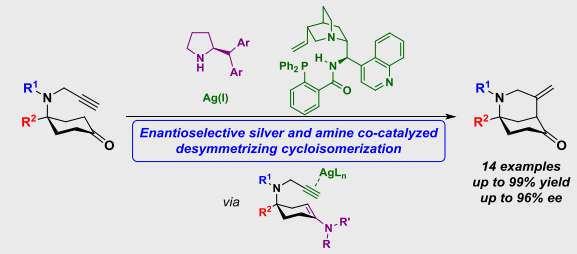

A silver(I) and amine co-catalyzed desymmetrization of 4-propargylamino cyclohexanones for the direct enantioselective synthesis of 2

azabicyclo[3.3.1]nonanes is described. A matching effect between a chiral aminocatalyst and a chiral ligand for silver is exploited. The reaction is efficient, broad in scope and proceeds with high enantioselectivity.
Rubén Manzano, Swarup Datta, Robert S. Paton, ${ }^{*}$ Darren J. Dixon*

Page No. - Page No.

Enantioselective silver and amine cocatalyzed desymmetrizing cycloisomerization of alkyne-linked cyclohexanones 